Submitted to International Journal of Fatigue - April 2019 Spec.Issue 'Fatigue in Structural Integrity of offshore Energy Industry'

\title{
FRETTING FAILURE OF A PRESSURE ARMOUR IN AN UNBONDED FLEXIBLE RISER
}

\author{
Sabrina Vantadori1, Andrea Carpinteri1, Ignacio Iturrioz ${ }^{2}$ \\ ${ }^{1}$ Department of Engineering \& Architecture, University of Parma, \\ Parco Area delle Scienze 181/A, \\ 43124 Parma, Italy \\ ${ }^{2}$ Mechanical Post- Graduate Program, \\ Federal University of Rio Grande do Sul, Sarmento Leite 425, \\ CEP 90050-170, Porto Alegre, Brazil
}

Corresponding author: sabrina.vantadorieunipr.it

\section{ABSTRACT (max 100 words)}

In the present paper, the failure of a pressure armour in a flexible riser under fretting wear loading is analysed. Fretting lifetime is evaluated through the multiaxial fatigue criterion by Carpinteri et al., implementing the critical direction method proposed by Araujo et al. to define the orientation of the critical plane. The fretting map (in terms of number of loading cycles to failure against displacement amplitude) is build starting from the simulation results of some fretting wear tests in partial slip regime. Then, such a map is compared with that determined by means of the results derived through a combined experimental and numerical methodology available in the literature. 
KEYWORDS: riser, partial slip, fretting, fretting map

\section{NOMENCLATURE}

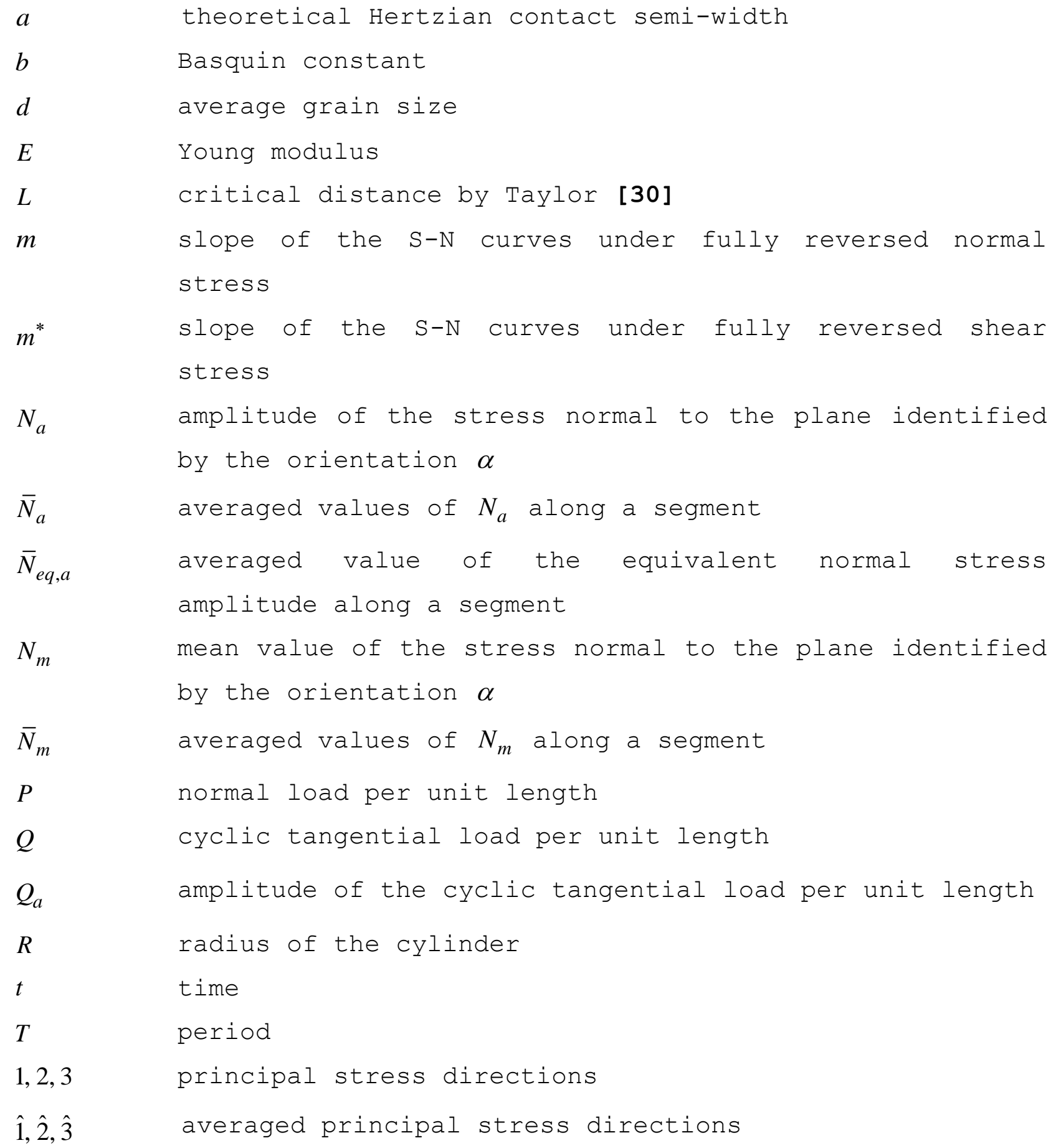




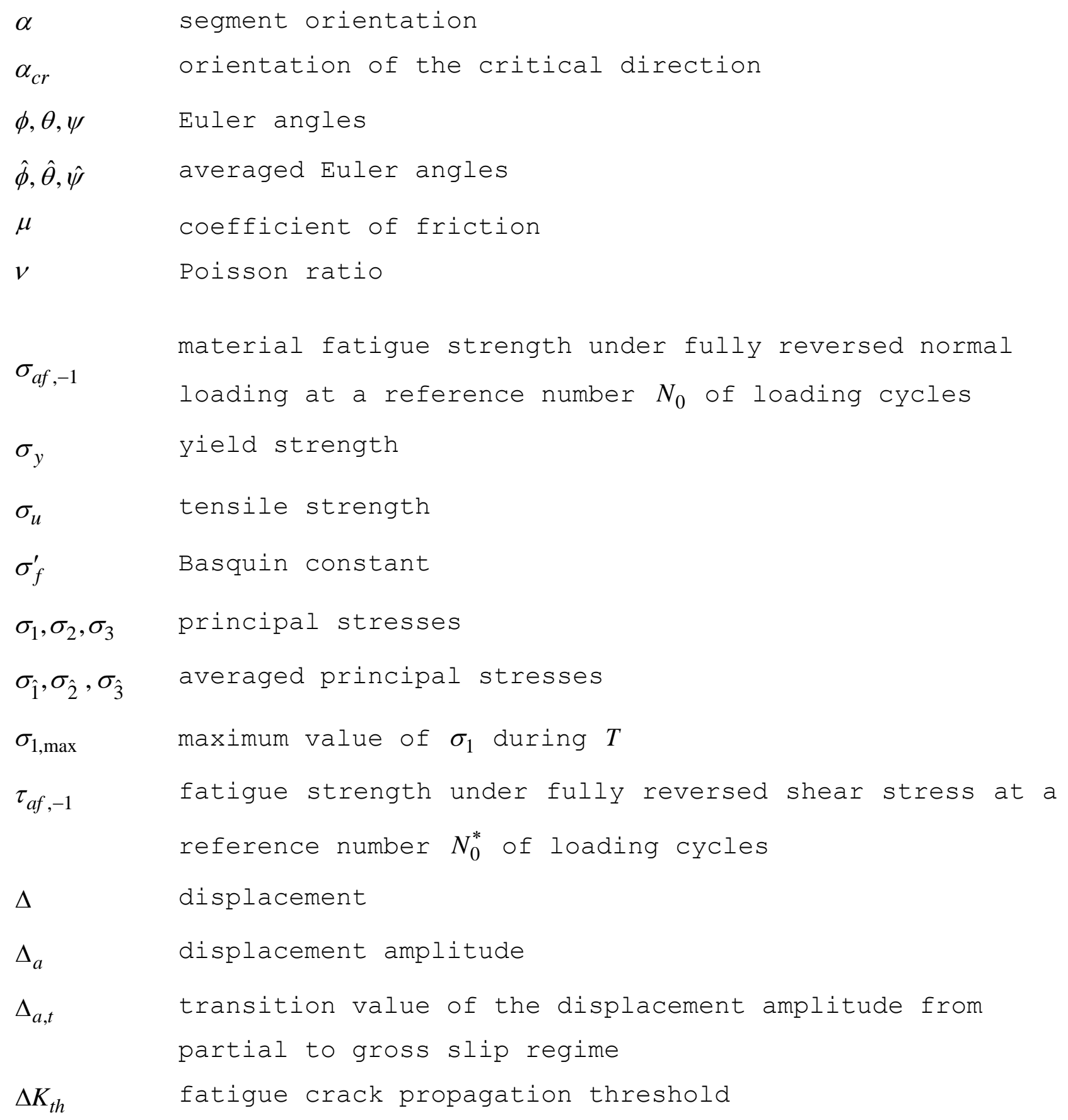




\section{INTRODUCTION}

Offshore oil and gas exploration and production in deepwater and ultra-deepwater scenarios require the use of highly sophisticated equipment and increasing innovative technology [1]. The failure of such an equipment can cause serious accidents, including loss of human lives and materials and environmental pollution [2].

In such a contest, offshore flexible pipes are used to transport hydrocarbons, natural gas, and condensates (low-density mixes of hydrocarbon liquids). Seabed flowlines and jumper cables can be found in static design. Flexible risers for the vertical transportation of fluids from seabed to production and drilling facilities can be found in dynamic design [1].

The cross-section of a flexible riser is complex, since it consists in a multi-layered cross-section composed by layers of steel, polymer, sheaths, and tapes. The layers can be either bonded or unbonded. In a bonded riser, each layer is bonded together by adhesives or vulcanization, the latter performed by applying heat together with pressure and, therefore, the crosssection can be considered as a single section. In an unbonded riser, instead, each layer can freely move against each other, sliding only under the effect of friction. The unbonded type is most common in offshore oil and gas exploration and production equipments .

The unbonded risers can be rough bore or smooth bore, where the rough bore (Figure $\mathbf{1}$ ) is the most common in the offshore industry. 
The inner layer of the rough bore riser is an interlocked stainless steel carcass. The function of this layer is to prevent collapse of the pressure plastic sheath, which is the next layer. The function of such a sheath is to ensure that riser remains leak proof. The pressure armour is the next layer, which is an helically wound steel layer (Figure 2); its function is to sustain the radial loading produced by internal pressure. Then, an antiwear tape allows to lessen fatigue and wear loading.

The cross-section presents two tensile layers, consisting in cross wound armour layers, whose function is to resist under tension and torque. Furthermore, such tensile layers sustain a significant portion of the radial loading produced by the pipe internal pressure, limiting the radial expansion of these two layers.

The final layer is a plastic sheath which protects the steel layer against sea corrosion and abrasion. Note that the steel layers are also subjected to fatigue corrosion due to gas and water vapour.

\section{Figure 2.}

The smooth bore riser differs from the rough bore one for the inner layer consisting in a plastic tube, and is used in applications which do not involve gas diffusion. 
Riser structural failure may result in reduction or cessation of production development, leading to serious financial losses, pollution, and even endangerment of human lives.

The number of potential failure modes in a flexible riser is very large, although modes experienced in service operation are more limited. The American Petroleum Industry (API) Recommended Practice 17B [4] lists and describes the potential failure modes for bonded and unbonded flexible risers. Between them, there is a failure mode named fatigue failure (more precisely, pressure armour wire fatigue).

As is shown in Figure 2, the pressure armour is made up of profiled steel wires wound with a helical shape. Such a profile, named Zeta or Flexlok, is still used in flexible riser although alternative profiles are available [4]. The wire profile here examined is such that it interlocks through nub and valley contacts. During service operation, the riser is subjected to both external and internal pressure, due to sea water and pumping fluids, respectively. The difference between external and internal pressure together with the interaction between the adjacent layers create a contact pressure on the nub and valley contacts. In an unbonded riser, its movements due to sea waves, displacement of floating facilities, and other dynamic forces create the ideal conditions for fretting phenomenon to occur. Although fatigue loading stresses the valley corners, such a phenomenon is not discussed in the present paper. 
In the present paper, the failure of a pressure armour in an unbonded rough bore flexible riser under fretting wear loading is analysed. Fretting lifetime of such a pressure armour is here evaluated through the multiaxial fatigue criterion by Carpinteri et al. [5-8], implementing the critical direction method proposed by Araujo et al. [9] to define the orientation of the critical plane. The accuracy of such a criterion is proved by comparing the simulation results with those obtained from a combined experimental and numerical methodology available in the literature $[10,11]$

\section{BASICS OF FRETTING}

Fretting phenomenon is a surface damage mechanism that occurs between contacting surfaces, experiencing the combination of normal loading and nano-/micro-scale relative slip $[12,13]$.

According to the cause that produces the relative slip, two types of loading condition can be distinguished: fretting wear and fretting fatigue [14-16]. Fretting wear loading condition is attained when at least one of the members of the contact is subjected to an external cyclic motion, whereas fretting fatigue loading condition is attained when at least one of the members of the contact is subjected to an external cyclic load.

Both conditions can occur in either partial slip or gross slip. According to the theoretical model by Mindlin [17], partial slip regime is attained when the tangential force remains lower than 
the product of the normal load and the static coefficient of friction, and there are parts of contact where no slip occurs. The fretting loop in a tangential force-displacement plane is elliptical [18]. Gross slip regime is attained when the tangential force is equal to the above product, and slip occurs across the whole contact. The fretting loop is trapezoidal [18].

To properly describe the mechanical behaviour under both fretting wear and fretting fatigue, the concept of fretting map can be exploited.

\subsection{The fretting maps}

A review of the main fretting maps available in the literature is given in Ref.[16]. The concept of fretting map under fretting wear loading condition was initially proposed by Vingsbo and Soderberg [19]. They built different fretting maps as a function of: normal force vs displacement amplitude, normal force vs tangential force, frequency of vibration vs displacement amplitude, and fretting wear rate (or fretting lifetime) vs displacement amplitude (or normal force, or frequency of vibration) .

Such fretting maps show the relevant regime of fretting contact, each of them characterized by a certain stick and slip condition (that is, no sliding, stick and slip, or slip), surface degradation (that is, fatigue, wear, or oxidation attack), and fretting loop shape (that is, linear, elliptical or trapezoidal). 
The above Authors (Ref.[19]) experimentally identified three regimes (Figure 3):

(a) stick regime, characterised by no sliding at the interface and, in the stick area, very limited wear and oxidation in correspondence of individual asperities, plastically sheared in fretting direction. The fretting loop collapses in a segment;

(b) mixed stick-slip regime, characterized by a central stick area and a surrounding annular slip area. Surface degradation is represented by: extensive crack formation (fatigue) in the slip area with release of particles from cracks (wear), and wear and oxidation at the shear fractured individual asperities in the stick area. The fretting loop has an elliptical shape;

(c) gross slip regime, characterized by slip that takes place across the whole contact area, extensive wear with sliding marks in fretting direction and material delamination and detach of particles, and oxidation with detach of oxide flakes. Wear and oxidation are strongly coupled in such a regime. The fretting loop has a trapezoidal shape.

\section{Figure 3 .}

Subsequently, Zhou et al. [20-22] proposed the running condition fretting map (RCFM), where the partitioned regions include partial slip regime, mixed fretting regime and gross slip regime, depending by both displacement amplitude and number of loading cycles. More precisely, the regimes experimentally identified are (Figure 4a): 
(i) partial slip regime attained for small displacement amplitude values where, during the entire test, the contact behaves as in partial slip regime described by Mindlin [17] or, in an equivalent way, in the mixed stick-slip regime described by Vingsbo and Soderberg [19]. The fretting loop has an elliptical shape during the whole test;

(ii) mixed fretting regime attained for intermediate displacement amplitude values, associated with an unstable fretting loop, where both periods with an elliptical shape and trapezoidal shape are observed. The Mindlin model is not valid in such a regime;

(iii) gross slip regime attained for large displacement amplitude values where, during the whole test, the contact behaves as in the gross slip regime described by both Mindlin [17] and Vingsbo and Soderberg [19]. The fretting loop has a trapezoidal shape during the test.

\section{Figure 4 .}

Note that the above Authors ignored the stick regime by Vingsbo and Soderberg suggesting, in agreement with Mindlin, that there are always some regions of the contact experiencing slip and, therefore, no stick regime can actually exist.

The regime definitions by zhou et al. are more realistic than those previously presented, because the Authors of Refs [17,19] neglected the early stage of fretting process (that is, what happens below $10^{4}$ loading cycles) and therefore were not able to capture the mixed fretting regime. 
The Authors of Refs [20-22] also proposed the material response fretting map (MRFM) [23], where partitioned regions include no damage domain, cracking domain, competition domain, and wear domain (Figure $4 \mathrm{~b}$ ).

Concerning the correspondence between RCFM and MRFM shown in Figure 4, partial slip regime is divided into a security domain, without damage, and a domain where cracking appears. Gross slip regime is associated with wear and oxidation. Mixed fretting regime generates competition between cracking and wear, being such a regime the most critical one for crack nucleation and propagation.

Maps for fretting fatigue loading condition are also available in the literature $[\mathbf{2 4}, \mathbf{2 5}]$.

\section{STEEL PRESSURE ARMOUR EXAMINED}

In the present paper, the steel pressure armour of the unbonded rough bore flexible riser discussed in Refs $[10,11]$ is examined (Figure 5) .

Normal forces due to both internal pressure (produced by pumping fluids) and external pressure (produced by sea water), keep the nubs and valleys of the pressure armour in contact. The movement of the riser (due to sea waves and displacement of floating facilities) and other dynamic forces (as for example those due to bending and fluctuation of fluid pressure) create the ideal conditions for fretting to occur.

\section{Figure 5 .}




\subsection{Material}

The mechanical properties of the pressure armour material were measured by the Authors of Refs $[10,11]$ through monotonic tensile tests using an Instron servo-hydraulic testing machine, where the tested specimens were extracted from a pre-service flexible riser. Such properties are listed in Table 1.

Table 1.

The chemical composition provided in Ref. [11] is that of EN8 steel (see Table 2), which is similar to that of the pressure armour.

Table 2 .

The Basquin constants, estimated by the above Authors using the universal slopes method [26,27], were equal to $\sigma_{f}^{\prime}=1710 \mathrm{MPa}$ and $b=-0.12$ (at failure) .

The fretting wear tests presented in Ref.[11] were not performed by the Authors on the pressure armour material, because both sizes and complex geometry of the pressure armour made impossible to extract specimens for laboratory scale fretting tests. They used specimens made of EN8 steel, with chemical composition and hardness similar to those of the pressure armour material. The stabilized value of the friction coefficient was found to be $\mu=0.75$. 


\subsection{Geometric and loading configuration}

A single nub and valley contact of the pressure armour profile (Figure 5) can be schematized as the cylinder-on-flat geometry shown in Figure 6.

According to the numerical simulations presented in Ref.[11], the radius $R$ of the cylinder was equal to $3 \mathrm{~mm}$. A normal load per unit length, $P$, equal to $50 \mathrm{~N} / \mathrm{mm}$, was applied to the cylinder together with a tangential displacement, $\Delta$, characterized by loading ratio equal to -1 and different values of amplitude $\left(0 \leq \Delta_{a} \leq 30 \mu m\right)$. The theoretical Hertzian contact semi-width, $a$, was equal to $0.043 \mathrm{~mm}$.

\section{Figure 6 .}

Note that the normal force $P$ derives from both internal pressure (produced by pumping fluids) and external pressure (produced by sea water), whereas the movement of the riser due to sea waves and displacement of floating facilities and other dynamic forces is simulated by the tangential displacement $\Delta$.

\section{THE MULTIAXIAL FATIGUE CRITERION BY CARPINTERI ET AL.}

The multiaxial fatigue criterion here employed to estimate the lifetime of the pressure armour described in section 3 is the stress-based critical plane criterion proposed by Carpinteri et al. [5-8]. The flowchart of the criterion is shown in Figure 7. 
Figure 7 .

Although the results available in the literature (derived from the experimental and numerical methodology [11]) are referred to both partial and gross slip regime, only the simulations under the partial slip regime are the subject of the present paper, the limit being dictated by the analytical method used to determine the stress field [28].

In partial slip regime, the stress field near the contact zone is evaluated through the closed-form analytical solution by Johnson [28], as is detailed in Ref.[29]. Linear elastic behaviour of the material is assumed. The geometrical sizes, mechanical properties and loading conditions here simulated are those discussed in section 3. Note that the amplitude of the cyclic tangential load per unit length, $Q_{a}$, is computed as a function of the displacement amplitude, $\Delta_{a}$, through a linear equation given by:

$$
Q_{a}=\frac{\mu P}{\Delta_{a, t}} \Delta_{a}=\frac{0.75 \cdot 50}{0.0038} \Delta_{a}
$$

being $\Delta_{a, t}$ the transition value of the displacement amplitude from partial to gross slip regime. Such a value, reported in Ref.[11], is equal to $3.8 \mu \mathrm{m}$.

\subsection{Critical plane orientation}

Once the stress field is known, the critical plane is determined according to the critical direction method proposed by Araujo et 
al. [9]. Note that, actually, the critical plane is a segment, the examined problem being two-dimensional.

Firstly, the hot-spot $H$ is determined on the half contact surface $(0 \leq x \leq a$ in Figure 8$)$, due to the symmetry of the problem being analysed. Such a point is characterized by the maximum value of the averaged maximum principal stress $\sigma_{\hat{1}}$ attained on the half contact surface during a loading cycle. Such a stress $\sigma_{\hat{1}}$ can be computed as is described in the following.

\section{Figure 8 .}

Let us consider the material points on the half contact surface. In each of such points, the principal stress directions 1,2,3 (being $\sigma_{1} \geq \sigma_{2} \geq \sigma_{3}$ ) are identified by means of the three Euler angles, $\phi, \theta, \psi$, measured with respect to the fixed frame $X Y Z$ shown in Figure 8. Since such angles are time-varying during a loading cycle, then $\phi, \theta, \psi$ are averaged by employing a weight function, $W$, that operates as follows [5]:

$$
\hat{\phi}=\int_{0}^{T} \phi(t) W(t) d t \quad \hat{\theta}=\int_{0}^{T} \theta(t) W(t) d t \quad \hat{\psi}=\int_{0}^{T} \psi(t) W(t) d t
$$

being $W(t)$ the function given by:

$$
W(t)= \begin{cases}0, & \sigma_{1}(t)<\sigma_{1, \max } \\ 1, & \sigma_{1}(t)=\sigma_{1, \max }\end{cases}
$$

where $t$ is the time, $T$ is the period of the cyclic load $Q$, and $\sigma_{1, \max }$ is the maximum value of $\sigma_{1}$ during $T$. 
Once the averaged principal stress directions $\hat{1}, \hat{2}, \hat{3}$ are determined, the corresponding averaged principal stresses $\sigma_{\hat{1}}, \sigma_{\hat{2}}, \sigma_{\hat{3}}$ are computed, and the point on the contact surface characterized by the maximum value of $\sigma_{\hat{1}}$ is taken as the hot-spot $H$.

According to the critical direction method [9], a segment emanating from the hot-spot (also named crack initiation point) with an orientation $\alpha$ is taken into account (Figure 8). A physical size is associated with such a plane: as a matter of fact, the segment has a length equal to $2 L$, where $L$ is the critical distance by Taylor and, for such an aspect, the method is similar to the Line Method by Taylor [30-33].

In Ref.[30] different procedures available in the literature to estimate the critical distance are listed. One of them exploits the fatigue crack propagation threshold, $\Delta K_{t h}$, to compute $L$. However, to the best knowledge of the present authors, the $\Delta K_{\text {th }}$ value for EN8 steel related to loading ratio equal to -1 (that is, the loading ratio of the tangential cyclic force per unit length, $Q$ [33]) is not available in the literature and, therefore, the above procedure cannot be applied.

According to the statement that $L$ values for fatigue in metallic materials are typically of the same order as the grain size magnitude [30], $L$ is here taken equal to the average grain size $d$, computed according the ASTM E112-13 standard [34] by starting from grain size number equal to 7 [35]. The calculated value is $d=30 \mu \mathrm{m}$. 
The values of the amplitude $N_{a}$ and the mean value $N_{m}$ of the stress normal to the plane identified by the orientation $\alpha$ are computed in each point along the segment, and the corresponding averaged values along the segment are given by:

$$
\begin{aligned}
& \bar{N}_{a}=\frac{1}{2 L} \int_{0}^{2 L} N_{a}(r, \alpha) d r \\
& \bar{N}_{m}=\frac{1}{2 L} \int_{0}^{2 L} N_{m}(r, \alpha) d r
\end{aligned}
$$

being $r$ and $\alpha$ the coordinates in the polar frame shown in Figure 8. Note that, when $N_{m}(r, \alpha)$ is negative (i.e. in the case of compressive stress), it is conservatively assumed to be equal to zero.

The averaged value of the equivalent normal stress amplitude along the segment is herein computed as was proposed by Carpinteri et al [5-8]:

$$
\bar{N}_{e q, a}=\bar{N}_{a}+\sigma_{a f,-1}\left(\frac{\bar{N}_{m}}{\sigma_{u}}\right)
$$

where $\sigma_{a f,-1}$ is the material fatigue strength under fully reversed normal loading at a reference number $N_{0}$ of loading cycles. The value of $\sigma_{a f,-1}$, computed from the Basquin constants given in Section 3, is equal to $140 \mathrm{MPa}$.

The procedure to identify the critical plane starts by analysing the initial value $\alpha=0^{\circ}$, and proceeds by increasing such an angle of an angular increment $\Delta \alpha=1^{\circ}$, up to $\alpha=180^{\circ}$ (Figure 7). 
For each of such orientations, $\bar{N}_{e q, a}$ is evaluated. The critical direction, corresponding to the critical plane, is determined as the orientation $\alpha_{c r}$ that maximises $\bar{N}_{e q, a}(\alpha)$ :

$$
\bar{N}_{e q, a}\left(\alpha_{c r}\right)=\max _{0^{\circ} \leq \alpha \leq 180^{\circ}}\left\{\bar{N}_{e q, a}(\alpha)\right\}
$$

Note that the original formulation of the critical direction method, instead, maximises a different fatigue parameter: alternatively, the Smith-Watson-Topper parameter, the Fatemi-Socie parameter, or the Modified wöhler Curve Method parameter [9].

\subsection{Lifetime evaluation}

The position of the critical point $P_{c r}$ where to perform the fretting fatigue assessment is proposed by the present authors to be on the critical plane (that is, on the segment characterised by the orientation $\alpha_{c r}$ ) at a distance equal to $2 d$ from the hot-spot, where $d$ is the average grain size (Figure 8 ).

At such a point $P_{c r}$, the amplitude and the mean value of normal stress, $N_{a}\left(2 d, \alpha_{c r}\right)$ and $N_{m}\left(2 d, \alpha_{c r}\right)$, are computed. Also the amplitude of the shear stress component, $C_{a}\left(2 d, \alpha_{c r}\right)$, is calculated according to the Maximum Rectangular Hull Method by Araujo et al. [33].

The number of loading cycles to failure, $N_{f, c a l}$, can be obtained from the following equation [29]:

$$
\sqrt{\left[N_{a}\left(2 d, \alpha_{c r}\right)+\sigma_{a f,-1} \frac{N_{m}\left(2 d, \alpha_{c r}\right)}{\sigma_{u}}\right]^{2}+\left(\frac{\sigma_{a f,-1}}{\tau_{a f,-1}}\right)^{2}\left(\frac{N_{f, c a l}}{N_{0}}\right)^{2 m}\left(\frac{N_{0}^{*}}{N_{f, c a l}}\right)^{2 m^{*}}\left[C_{a}\left(2 d, \alpha_{c r}\right)\right]^{2}}=\sigma_{a f,-1}\left(\frac{N_{f, c a l}}{N_{0}}\right)^{m}
$$


where $m$ and $m^{*}$ are the slopes of the S-N curves under fully reversed normal and shear stress, respectively, and $\tau_{a f,-1}$ is the fatigue strength under fully reversed shear stress at a reference number $N_{0}^{*}$ of loading cycles.

The value of $m$ computed from the Basquin coefficient $b=-1 / m$ given in section 3 is equal to 9, whereas $\tau_{a f,-1}$ is assumed to be equal to $\sigma_{a f,-1} / \sqrt{3}=81 \mathrm{MPa}$, typical value assumed in the literature when no experimental data are available [36].

\section{RESULTS}

Five fretting tests under wear fretting loading condition are here simulated. The geometric and loading configurations are presented in Section 3.2, and five values of the displacement amplitude are examined: $\Delta_{a}=1.0,1.5,2.0,3.0$, and 3.8um. According to Eq. (1), the corresponding values of $Q_{a} / P$ are: $0.198,0.296,0.394,0.592$, and 0.75 .

For the examined loading configurations, point $H$ is always located at the trailing edge (that is, $x=a$ in Figure 8). The values of the orientation $\alpha_{c r}$ of the critical direction are listed in Table 3.

\section{Table 3 .}


In the case of $\Delta_{a}=3.8 \mu \mathrm{m}$, the graph of $\bar{N}_{e q, a}(\alpha)$ against $\alpha$ is plotted in Figure 9 for $0^{\circ} \leq \alpha \leq 90^{\circ}$.

\section{Figure 9.}

For each value of $\Delta_{a}$, the graph of $N_{a}\left(r, \alpha_{c r}\right)$ against the normalised distance $r / 2 L$ is shown in Figure 10.

Figure 10.

The fretting map, in terms of number of loading cycle to failure against displacement amplitude, built by starting from the simulation results of the above fretting wear tests under partial slip regime is shown in Figure 11. Such a result is compared with the numerical data reported in Ref.[11].

Figure 11

The coefficient of determination is equal to about 0.7 . Therefore, the comparison can be considered quite satisfactory, even taking into account that most of the parameters used applying the multiaxial fatigue criterion by Carpinteri do not come from experimental tests on the pressure armour material but they are related to EN8 steel and taken from the literature.

Unfortunately, the Authors of Ref.[11] did not perform any experimental campaign to build a fretting map to be compared to the numerical one. 


\section{CONCLUSIONS}

In the present paper, the failure of a pressure armour in an unbonded rough bore flexible riser under fretting wear loading condition has been analysed.

Fretting lifetime evaluation of such a pressure armour has been performed through the multiaxial fatigue criterion by carpinteri et al., implementing the critical direction method proposed by Araujo et al. to define the orientation of the critical plane.

The fretting map regarding the partial slip regime, in terms of fatigue life against the number of loading cycle to failure, has been built by starting from the simulation of some fretting wear tests.

The accuracy of such a criterion has been proved by comparing such a map with the results deduced by applying a combined experimental and numerical methodology available in the literature.

The accuracy of the Carpinteri criterion seems to be promising to estimate fretting lifetime for the examined case, but further comparisons with experimental test results are needed.

\section{ACKNOWLEDGEMENTS}

The authors gratefully acknowledge the financial support provided by the Italian Ministry for University and Technological and Scientific Research (MIUR), Research Grant PRIN 2015 No. 
2015JW9NJT on "Advanced mechanical modeling of new materials and structures for the solution of 2020 Horizon challenges".

\section{REFERENCES}

[1] Drumond G.P., Pasqualino I.P., Pinheiro B.C., Estefen S.F., Pipelines, risers and umbilicals failures: A literature review. Ocean Engineering 2018; 148: 412-425.

[2] Song X., Wang S., A novel spectral moments equivalence based lumping block method for efficient estimation of offshore structural fatigue damage. International Journal of Fatigue 2019; $118: 162-175$.

[3] Moore F. Materials for flexible riser systems: problems and solutions, Engineering Structures 1989; 1: 208-216.

[4] API RP 17B, Recommended Practice for Flexible Pipe, Fifth Edition, 2014.

[5] Carpinteri A., Karolczuk A., Macha E., Vantadori S., Expected position of the fatigue fracture plane by using the weighted mean principal Euler angles, International Journal of Fracture, 2002; 115: $87-99$.

[6] Carpinteri A., Spagnoli A., Vantadori S., Multiaxial fatigue assessment using a simplified critical plane-based criterion. International Journal of Fatigue 2011; 33: 969-976.

[7] Carpinteri A., Ronchei C., Spagnoli A., Vantadori S., On the use of the Prismatic Hull method in a critical plane-based multiaxial fatigue criterion. International Journal of Fatigue $2014 ; 68: 159-167$.

[8] Carpinteri A., Berto F., Campagnolo A., Fortese G., Ronchei C., Scorza D., Vantadori S., Fatigue assessment of notched specimens by means of a critical plane-based criterion and energy concepts. Theoretical and Applied Fracture Mechanics, Special Issue on Notch Mechanics 2016; 84: 57-63. 
[9] Araújo J.A., Almeida G.M.J., Ferreira J.L.A., da Silva C.R.M., Castro F.C., Early cracking orientation under high stress gradient: the fretting case. International Journal of Fatigue $2017 ; 100: 302-311$.

[10] O'Halloran S.M., Connaire A.D., Harte A.M., Leen S.B., Modelling of fretting in the pressure armour layer of flexible marine risers, Tribology International 2016; 100: 306-316.

[11] O'Halloran S.M., Shipway P.H., Connaire A.D., Leen S.B., Harte A.M., A combined wear-fatigue design methodology for fretting in the pressure armour layer of flexible marine risers, Tribology International 2017; 108: 7-15.

[12] Ashton P.J., Harte A.M., Leen S.B., A strain-gradient, crystal plasticity model for microstructure-sensitive fretting crack initiation in ferritic-pearlitic steel for flexible marine risers, International Journal of Fatigue 2018; 111: 81-92.

[13] Sunde S.L., Berto F., Haugen B., Predicting fretting fatigue in engineering design, International Journal of Fatigue 117 (2018) $314-326$.

[14] Waterhouse R.B., Fretting fatigue. International Materials Reviews 1992; 37: 77-97.

[15] Fouvry S., Kapsa Ph., Vincent L., Developments of fretting sliding criteria to quantify the local friction coefficient evolution under partial slip condition, Tribology Series 1998; 34 : $161-172$.

[16] Zhoua Z.R., Nakazawa K., Zhu M.H., Maruyama N., Kapsa Ph., Vincent L., Progress in fretting maps, Tribology International 2006; 39: 1068-1073.

[17] Mindlin RD. Compliance of elastic bodies in contact. ASME J. Appl. Mech. 1949;16:259-68.

[18] Hannel S., Fouvry S., Kapsa Ph., Vincent L., The fretting sliding transition as a criterion for electrical contact performance, Wear 2001; 249: 761-770.

[19] Vingsbo O., Soderberg S., On fretting map, Wear 1988; 126: $131-147$. 
[20] Zhou Z.R., Pellerin V., Vincent L., Wear mechanisms in fretting of aluminium alloys, In: Proceedings of the second international conference on aluminium alloys, 1990, Beijing, China, p. 642-647.

[21] Zhou Z.R., Fayeulle S., Vincent L., Cracking behaviour of various aluminium alloys during fretting wear. Wear 1992; 155: $317-30$.

[22] Zhou Z.R., Vincent L., Mixed fretting regime. Wear 1995; 181$183: 531-6$.

[23] Heredia S., Fouvry S., Introduction of a new sliding regime criterion to quantify partial, mixed and gross slip fretting regimes: Correlation with wear and cracking processes, Wear 2010; 269: 515-524.

[24] Petiot C., Vincent L., Dang Van K., Maouche N., Foulquier J., Journet B., An analysis of fretting fatigue failure combined with numerical calculations to predict crack nucleation, Wear 1995; 181-183: 101-11.

[25] Nakazawa K., Sumita M., Maruyama N., Effect of relative slip amplitude on fretting fatigue of high strength steel, Fatigue Fract. Eng. Mater Struct. 1994; 17: 751-9.

[26] Manson S.S., Fatigue: a complex subject-some simple approximations, Experimental Mechanics 1965; 5: 193-226.

[27] Cruzado A., Leen S.B., Urchegui M.A., Gómez X., Finite element simulation of fretting wear and fatigue in thin steel wires, International Journal of Fatigue, 2013; 55: 7-21.

[28] Johnson K.L. Contact mechanics. Cambridge, UK: Cambridge University Press; 1985.

[29] Vantadori S., Fortese G., Ronchei C., Scorza D., A stress gradient approach for fretting fatigue assessment of metallic structural components. International Journal of Fatigue 2017; 101: $1-8$.

[30] Taylor D., The theory of critical distances: a new perspective in fracture mechanics. Elsevier Science; 2007. 
[31] Bowen L., Xiangqiao Y., An extension research on the theory of critical distances for multiaxial notch fatigue finite life prediction, International Journal of Fatigue 2018; 117: 217-229.

[32] Dabiria M., Lindroos M., Andersson T., Afkhami S., Laukkanen A., Björka T., Utilizing the theory of critical distances in conjunction with crystal plasticity for low-cycle notch fatigue analysis of S960 MC high-strength steel, International Journal of Fatigue 2018; 117: 257-273.

[33] Susmel L., The Theory of Critical Distances: applications in fatigue. In: Proc. of ECF 16, Alexandroupolis, Greece, 2006.

[34] ASTM E112 - 13, Standard Test Methods for Determining Average Grain Size.

[35] Sharma S.S., Mallarapu A., Upparapalli H., Rai C., Effects of Thermal Treatment on Mechanical Properties and Grain size of En8 Steel, Journal of Mechanical Engineering and Biomechanics 2016; 1 : $64-68$.

[36] Susmel L., Multiaxial Notch Fatigue: from nominal to local stress-strain quantities. Woodhead \& CRC, Cambridge, UK. 
Submitted to International Journal of Fatigue - April 2019

Spec.Issue 'Fatigue in Structural Integrity of Offshore Energy Industry'

\section{FRETTING FAILURE OF A PRESSURE ARMOUR}

\section{IN AN UNBONDED FLEXIBLE RISER}

Sabrina Vantadori1, Andrea Carpinteri1, Ignacio Iturrioz ${ }^{2}$

${ }^{1}$ Department of Engineering \& Architecture, University of Parma, Parco Area delle Scienze 181/A, 43124 Parma, Italy

2Mechanical Post- Graduate Program, Federal University of Rio Grande do Sul, Sarmento Leite 425, CEP 90050-170, Porto Alegre, Brazil

Corresponding author: sabrina.vantadadori@unipr.it

FIGURES AND TABLES 


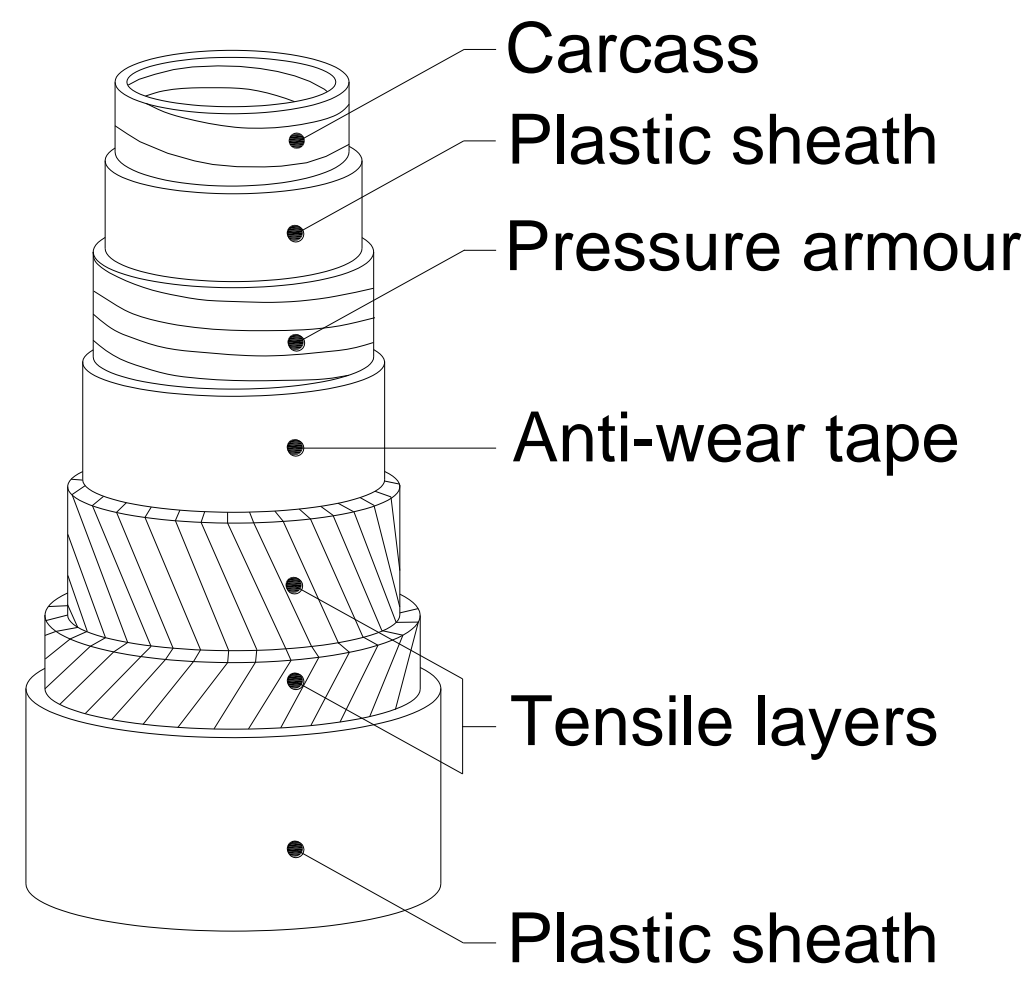

Figure 1. Unbonded flexible riser cross-section.

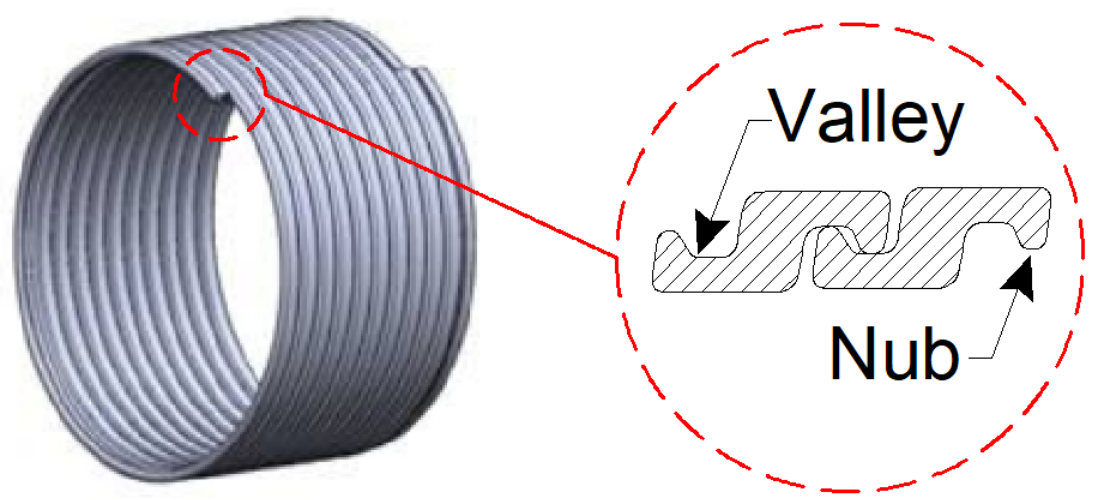

Figure 2. Pressure armour made up of a profiled steel helically wires wound. The pressure armour profile consists in nub and valley contacts. 


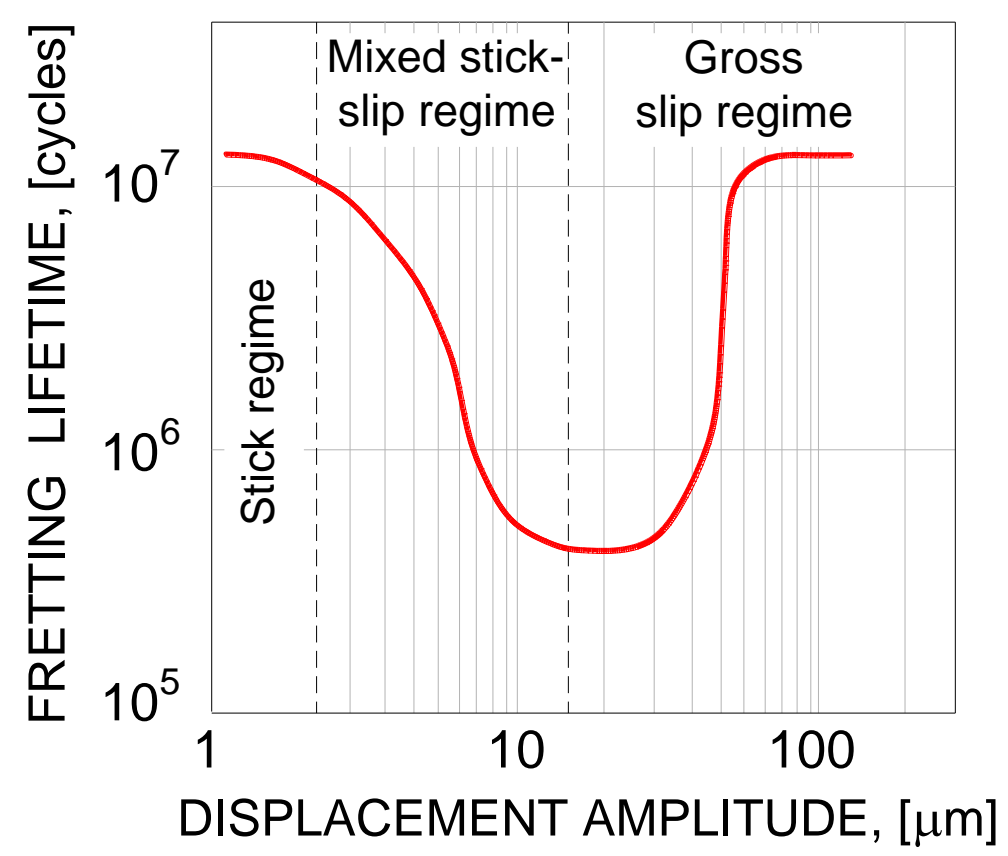

Figure 3. An example of fretting map under fretting wear loading condition [19]: fretting lifetime vs displacement amplitude. 


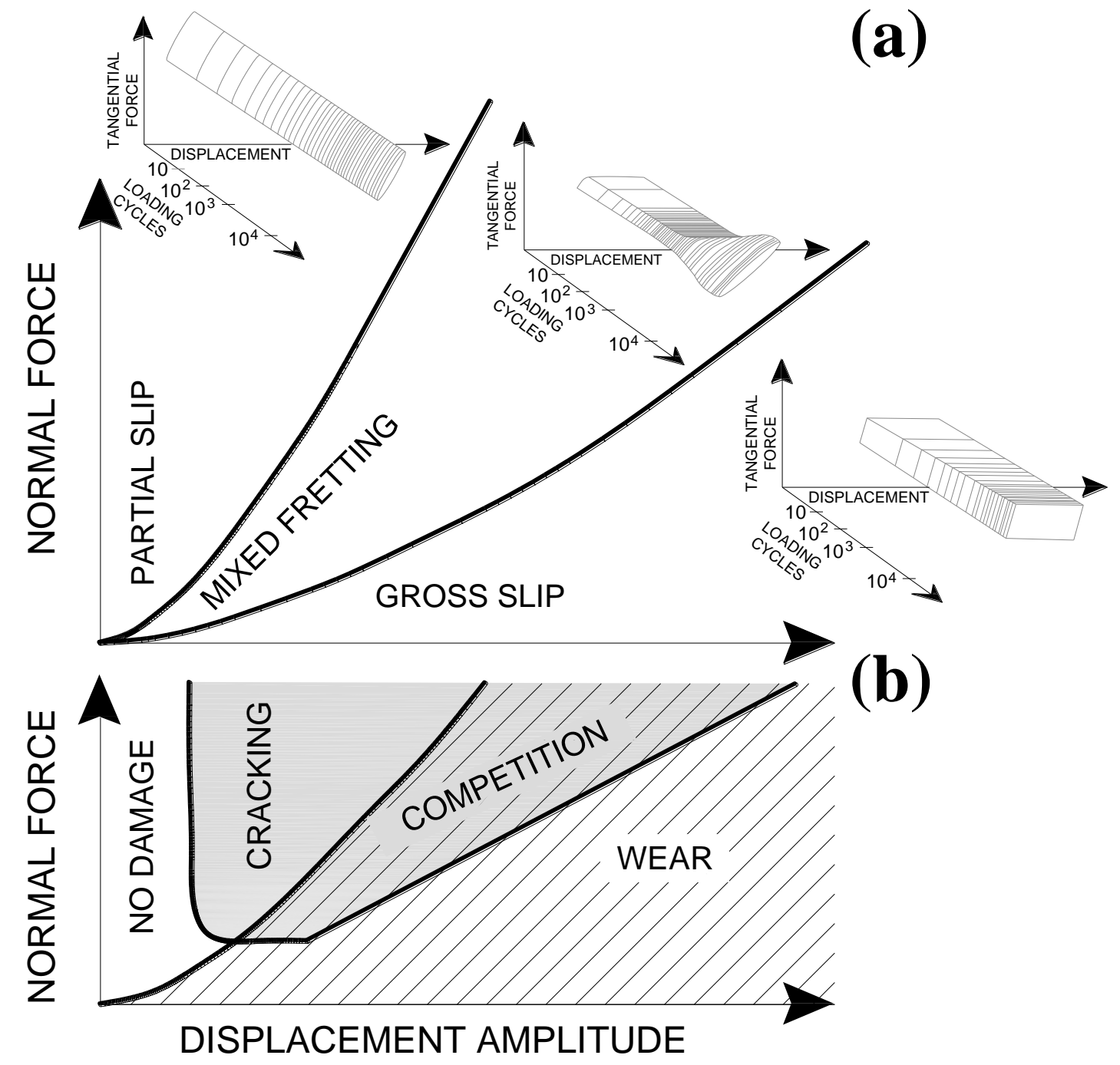

Figure 4. Fretting maps: (a) running condition fretting, and (b) material response fretting map.

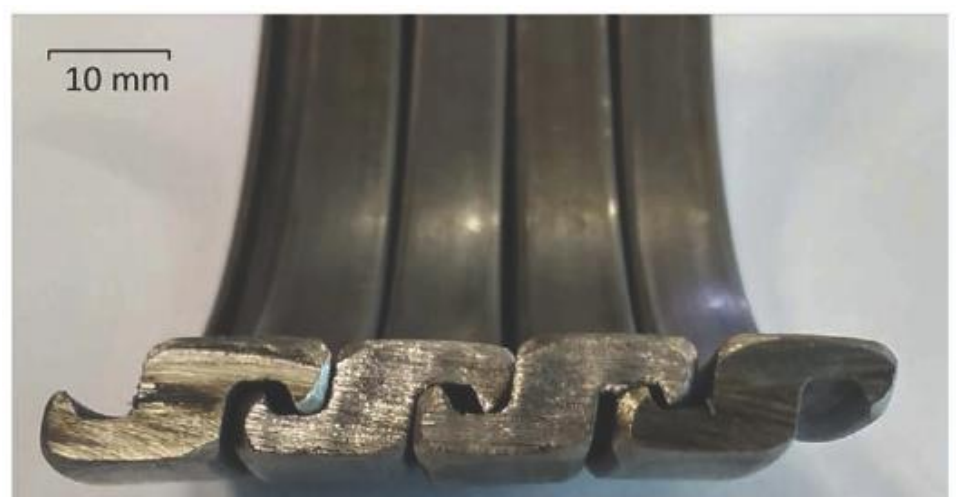

Figure 5. Pressure armour analysed in Refs $[10,11]$. The picture is taken from Ref.[11]. 
Table 1. Mechanical properties for pressure armour material [11].

\begin{tabular}{lll}
\hline PROPERTY & & \\
\hline Young's modulus & $E$ & $189 \cdot 10^{3} \mathrm{MPa}$ \\
\hline Poisson's ratio & $v$ & 0.3 \\
\hline Yield strength & $\sigma_{y}$ & $750 \mathrm{MPa}$ \\
\hline Tensile strength & $\sigma_{u}$ & $882 \mathrm{MPa}$ \\
\hline
\end{tabular}

Table 2. Material chemical composition of EN8 steel [11].

\begin{tabular}{lllllll}
\hline Element & $\mathrm{Fe}$ & $\mathrm{C}$ & $\mathrm{Mg}$ & $\mathrm{Si}$ & $\mathrm{P}$ & $\mathrm{S}$ \\
\hline Weight [\%] & Balance & $0.36-0.44$ & $0.60-1.00$ & $0.10-0.40$ & $0.05 \max$ & $0.05 \max$ \\
\hline
\end{tabular}




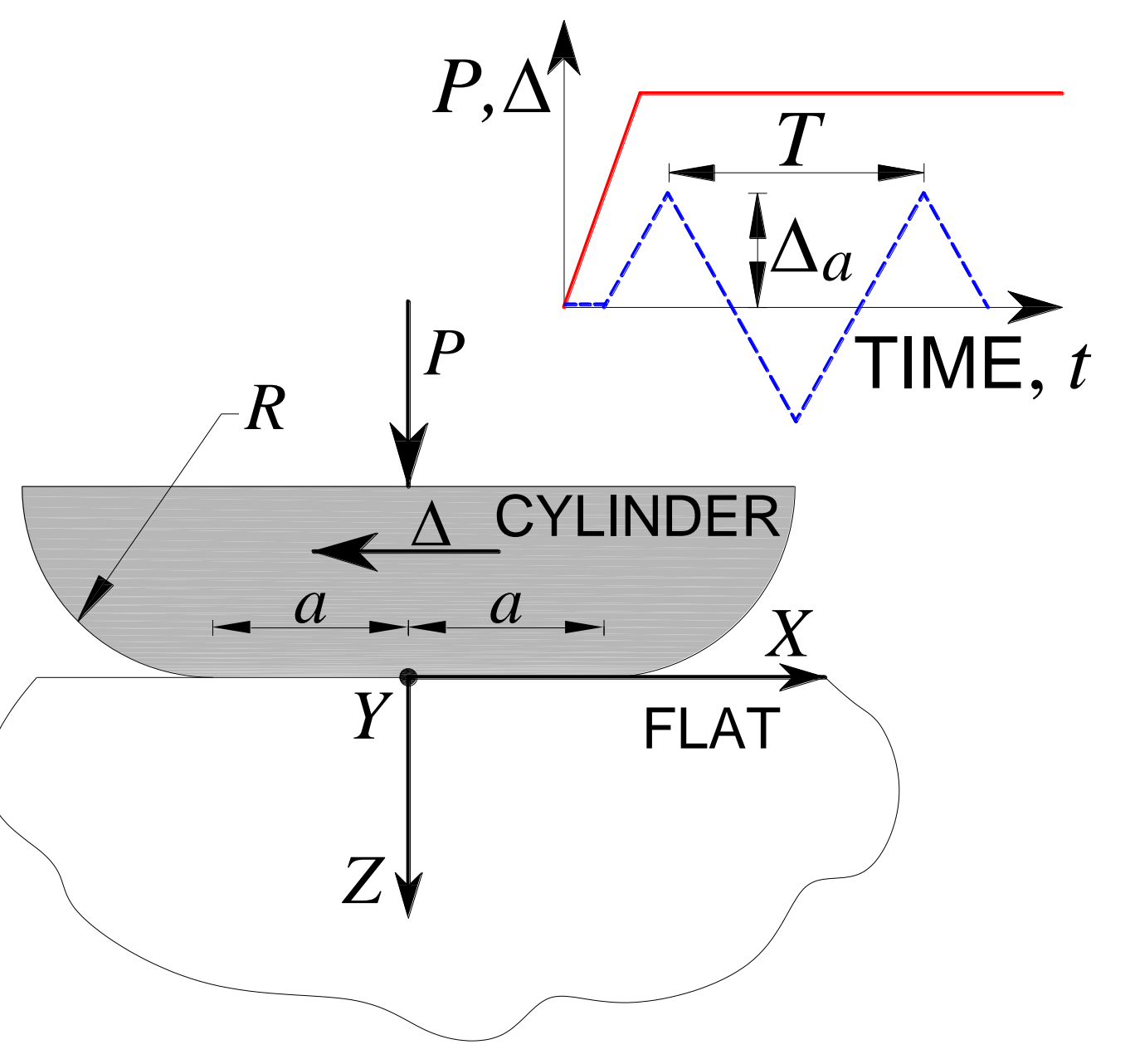

Figure 6. Cylinder-on-flat geometry. 


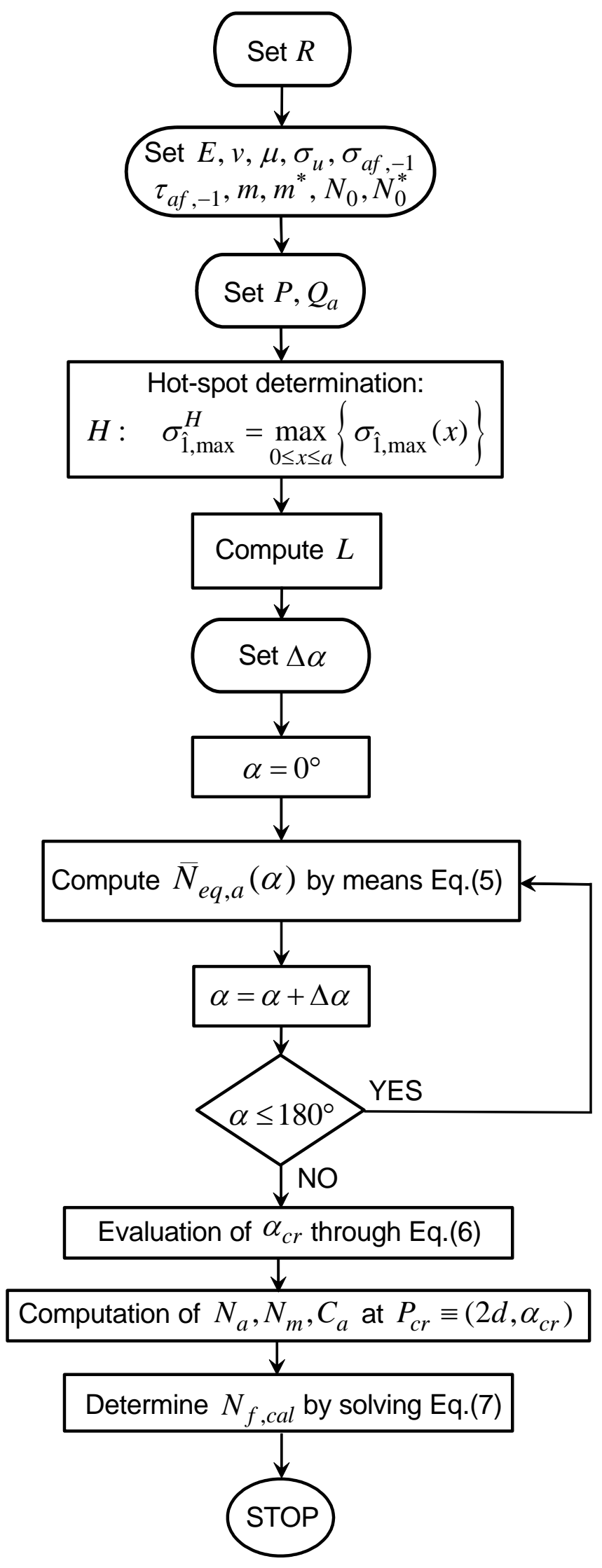

Figure 7. Flowchart of the Carpinteri et al. criterion. 


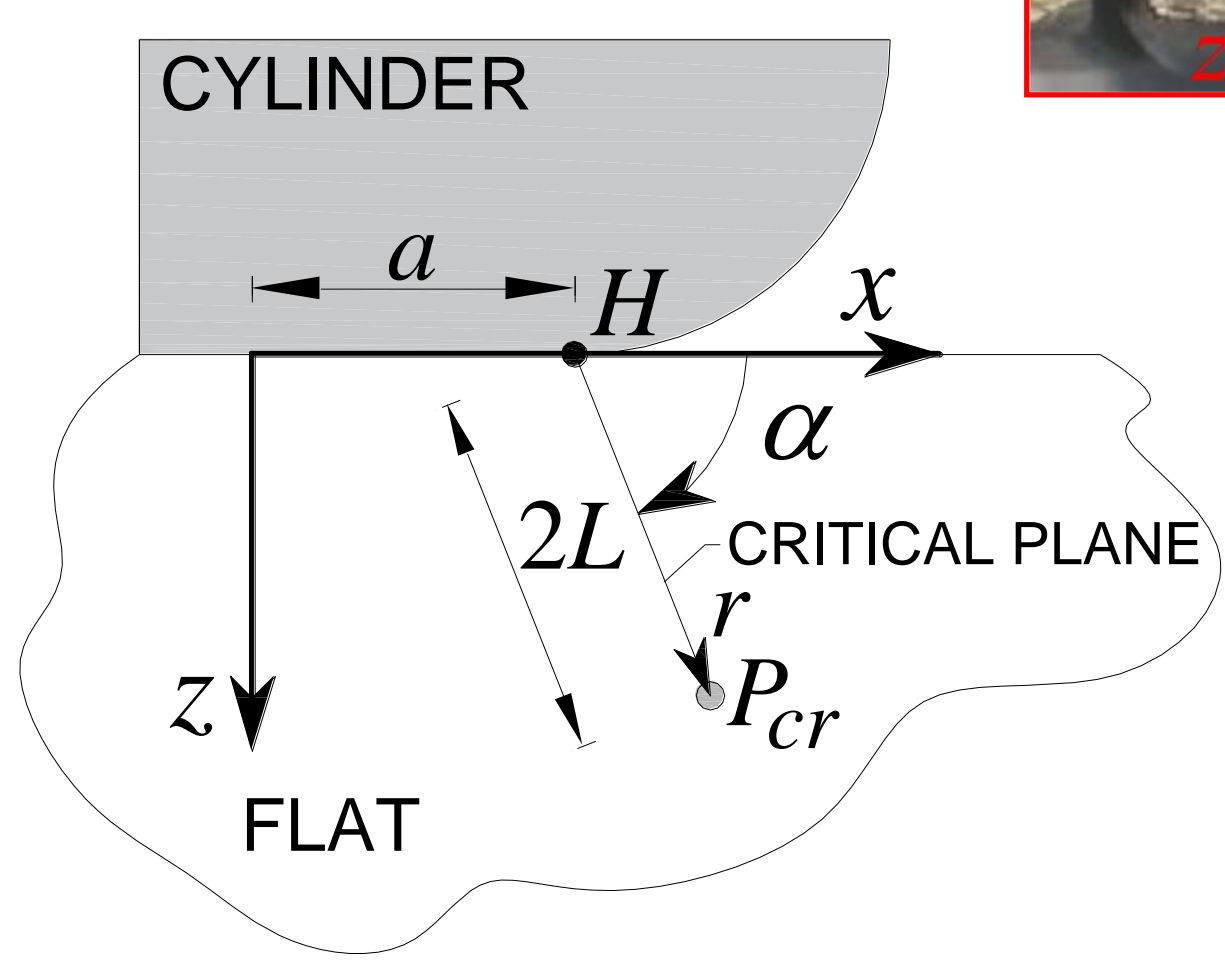

Figure 8. Cylinder-on-flat geometry: procedure to determine the critical plane orientation. The picture of the pressure armour analysed $[10,11]$ together with the reference frames here employed are shown on the right-hand side of the Figure. 
Table 3. Values of the orientation of the critical direction, $\alpha_{c r}$, corresponding to certain values of $\Delta_{a}$ and $Q_{a} / P$.

\begin{tabular}{lll}
\hline$\Delta_{a}[\mu \mathrm{m}]$ & $Q_{a} / P$ & $\alpha_{c r}\left[{ }^{\circ}\right]$ \\
\hline 1.0 & 0.198 & 7 \\
\hline 1.5 & 0.296 & 10 \\
\hline 2.0 & 0.394 & 11 \\
\hline 3.0 & 0.592 & 15 \\
\hline 3.8 & 0.75 & 10 \\
\hline
\end{tabular}

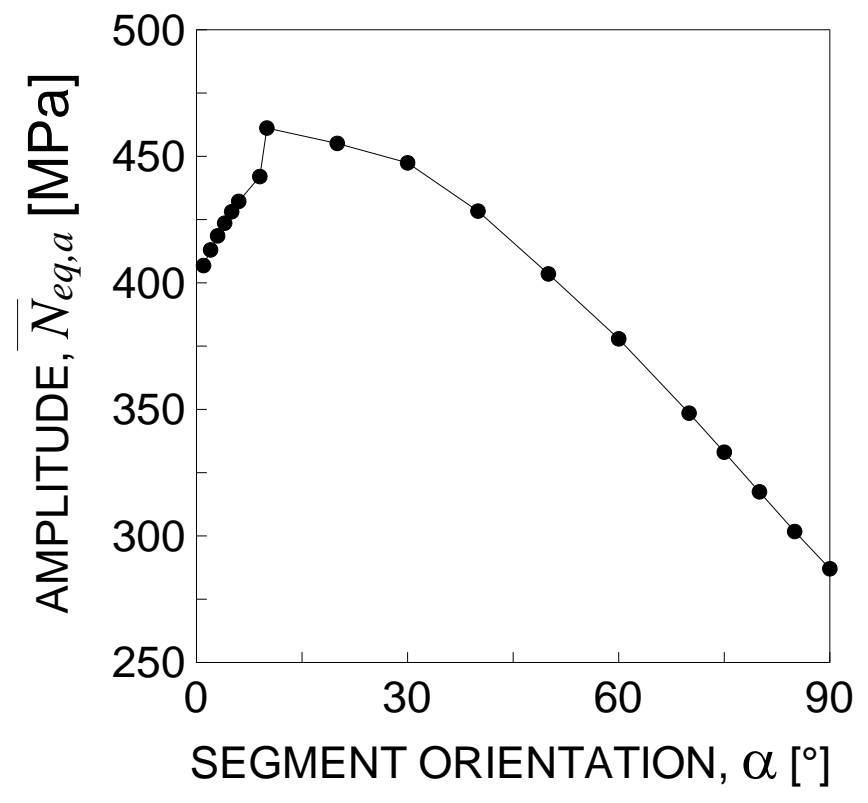

Figure 9. Graph of $\bar{N}_{e q, a}(\alpha)$ against $\alpha\left(0^{\circ} \leq \alpha \leq 90^{\circ}\right)$ for $\Delta_{a}=3.8 \mu \mathrm{m}$. 


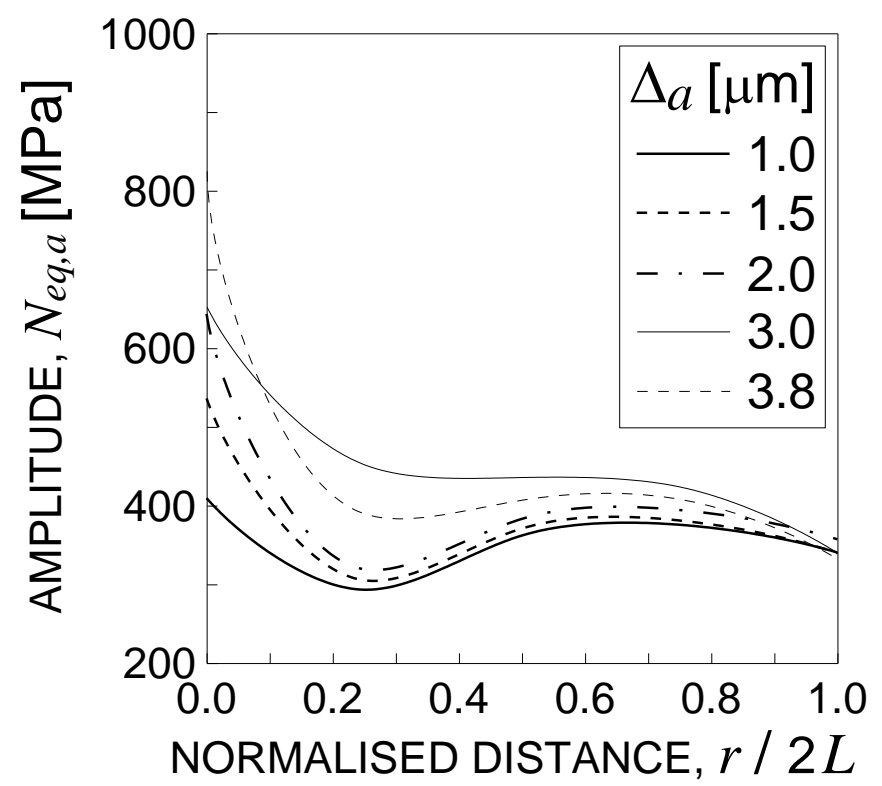

Figure 10. Graphs of $N_{e q, a}\left(r, \alpha_{c r}\right)$ against the normalised distance $r / 2 L$ for $\Delta_{a}=1.0,2.0,2.5,3.0$, and $3.8 \mu \mathrm{m}$.

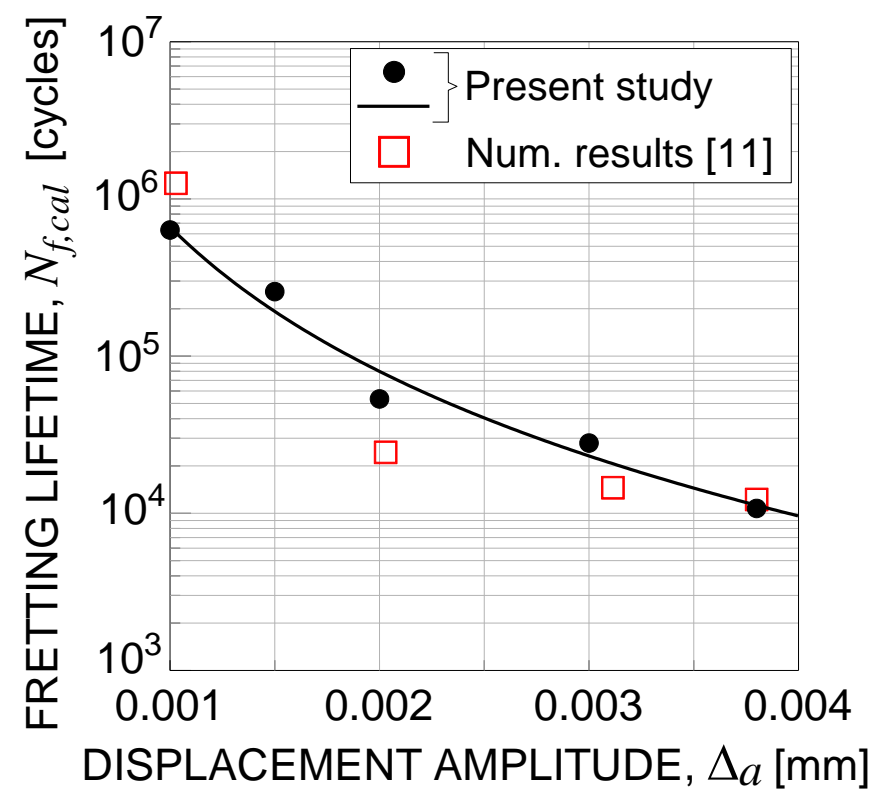

Figure 11. Fretting map in terms of number of loading cycle to failure against displacement amplitude: present results and numerical results from Ref.[11]. 